\title{
Congenital Maxillary Double Lip: A Case Report
}

\author{
Dr. Kashmira Pokhrel, ${ }^{1}$ Dr. Sajeev Shrestha, ${ }^{1}$ Dr. Shivalal Sharma ${ }^{1}$ \\ ${ }^{1}$ Department of Periodontology and Oral Implantology, BP Koirala Institute of Health Sciences,
} Dharan, Sunsari, Nepal.

\begin{abstract}
A double lip is an infrequent anomaly that may either be congenital or acquired. It commonly affects the upper lip with more predilection in males. Double lip may require surgical correction for aesthetic or masticatory reasons. Treatment includes excision of the mucosa and submucosal tissue that gives good result. A 19-year-old male presented with bulge under central portion of upper lip with no constriction. Surgical correction was done using an elliptical incision to remove excess mucosal tissues. Satisfactory aesthetic result was obtained with an uneventful healing.

Keywords: Aesthetics; double lip; surgical correction.
\end{abstract}

\section{INTRODUCTION}

Double lip is an unusual abnormality that may be congenital or acquired. It is defined as the appearance of excess tissue in area of lips wet line during functional lip movements. ${ }^{1}$ It commonly affects upper lip but its presentation in lower lip or both upper and lower lip has also been documented. ${ }^{2}$ It commonly affects male in the ratio $7: 1 .^{3}$

Double lip might pose cosmetic problems, especially during smiling, leading to an unsightly appearance. ${ }^{4}$ Surgical excision is the treatment of choice for correction of double lip. ${ }^{5}$ The present article reports a case of maxillary double lip and its surgical correction.

\section{CASE REPORT}

A 19-year-old male presented to the department of Periodontology and Oral Implantology, BP Koirala Institute of Health Sciences, Dharan with the chief complaint of thick bulging out tissue under upper lip, which made him aesthetically concerned in front of his friends while talking or smiling. This deformity was observed by the patient since his childhood and became more prominent as he grew up. He had no history of trauma, and no contributory family and medical history.

On examination, an additional fold of mucosal tissue without a central constriction was observed on the inner aspect of the

Correspondence
Dr. Kashmira Pokhrel
Email: kashmirapokhrel@gmail.com
Citation
Pokhrel K, Shrestha S, Sharma S. Congenital Maxillary Double
Lip: A Case Report. J Nepal Soc Perio Oral Implantol. 2021 Jan-
Jun;5(9):61-3.

upper lip while smiling (Figure 1). The tissue was not observed when the patient's lip was in rest position but was prominent on speaking and smiling. The tissue was pale pink in colour, smooth, and soft in consistency. The maxillary labial frenal attachment was gingival with retraction of papilla during functional movements. Other oral tissues were under normal limits. On clinical examination, blepharochalasis and thyroid enlargement as seen in Ascher's syndrome were absent. The routine blood profile was within normal limits. Based on the history and clinical examination, diagnosis of maxillary double lip was made. Verbal consent was obtained from the patient. Hence, surgical excision was planned under local anaesthesia.

Local infiltration was chosen as the method of administering anaesthesia. After the infiltration anaesthesia, excess fold of tissues along with some minor salivary glands were removed with a transverse elliptical incision and frenectomy was also performed in the same appointment (Figure 2). Haemostasis was achieved successfully, and simple interrupted 4-0 silk sutures were placed for approximation (Figure 3). Analgesic (Ibuprofen $400 \mathrm{mg}$ ) thrice-daily for two days was prescribed for post-operative pain management. Thorough oral hygiene and post-operative care instructions were given. Chlorhexidine mouthwash $0.2 \%$ twice daily for two weeks was prescribed.

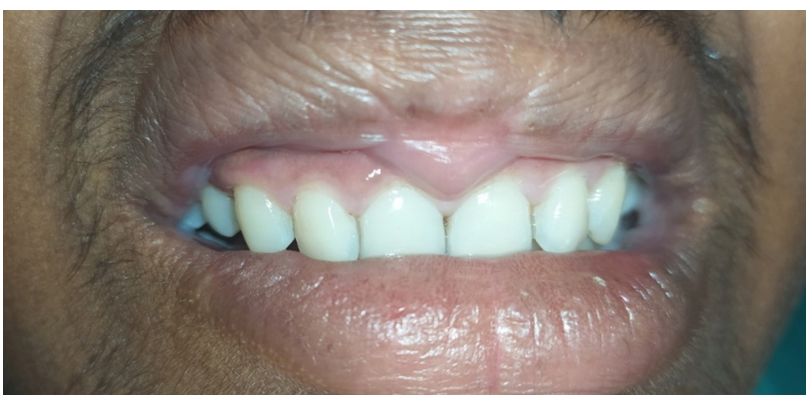

Figure 1: Maxillary double lip.

This is an open access journal, and articles are distributed under the terms of the Creative Commons Attribution CC BY 4.0 Licence. 


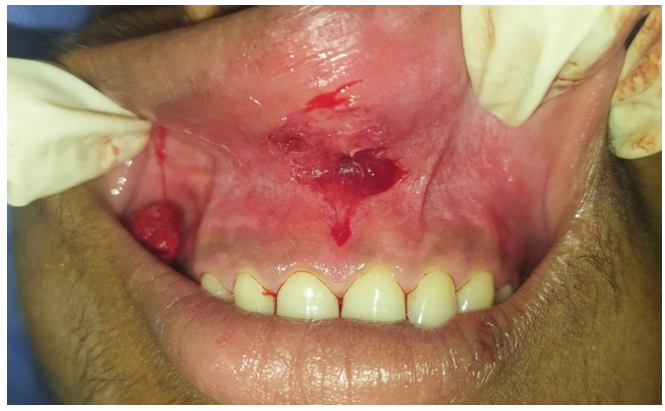

Figure 2: Excision of mucosal tissues along with frenum.

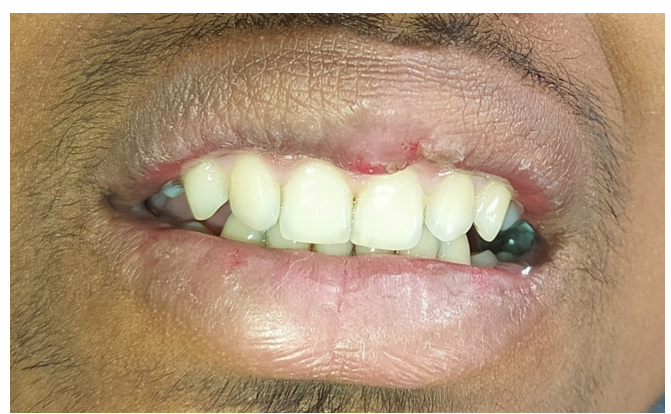

Figure 4: Healing at 10 days.

The patient was recalled after 10 days and sutures were removed (Figure 4). Healing was uneventful and the patient was satisfied with the postoperative result. He was evaluated after two months and kept on further follow-up (Figure 5).

\section{DISCUSSION}

Double lip is an extremely infrequent lip abnormality when present causes significant difficulties in speech, mastication, and aesthetic point of view. ${ }^{6}$ Usually, double lip is not quite observed when the lips are at rest but the excess fold of tissue projects beyond the vermilion border when the lip is retracted as during smiling, laughing or, talking. ${ }^{5}$ There were no functional disturbances in our patient, but the patient was psychologically disturbed due to the appearance, especially, when smiling and talking.

Although the exact aetiology of the double lip is unknown, exaggeration of horizontal sulcus between the pars glabrosa and the pars villosa during the development of the lips is thought to be the reason for congenital double lip. ${ }^{4,5}$ The activity of orbicularis oris causes the muscle fibres to stretch and the extra tissue mass which has no fibre penetration droops down that becomes visible as a second upper lip. ${ }^{2,3}$ It has been found to be associated with Ascher syndrome, a triad of double upper lip, blepharochalasis, and nontoxic thyroid enlargement or alone. ${ }^{7}$ Acquired double lip can occur after a trauma or due to habitual pulling of the mucosa through median diastema. ${ }^{3}$ Its association with other oral anomalies, such as bifid uvula, cleft palate, haemangiomas, and cheilitis glandularis has also been reported. ${ }^{3}$ Differential

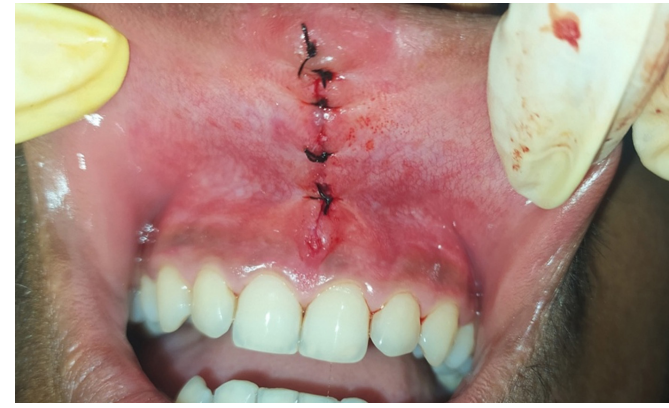

Figure 3: Silk sutures 4-0 placed.

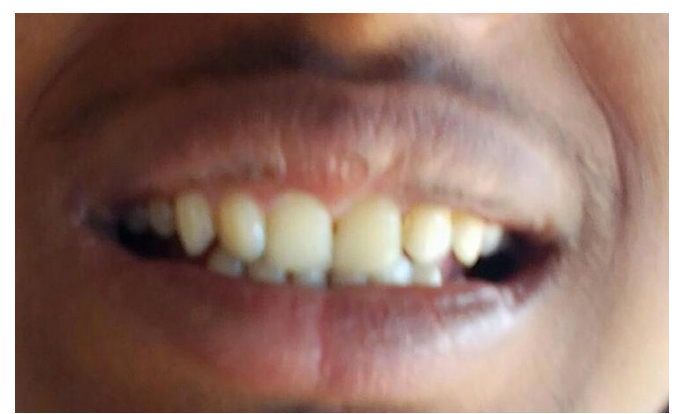

Figure 5: Post-operative follow-up after two months.

diagnosis of double lip is haemangioma, lymphangioma, angioedema, and cheilitis glandularis. ${ }^{2}$ The diagnosis of congenital double lip was made as the patient presented with the history of the abnormality since his childhood that became more prominent with his increasing age.

The treatment of choice for double lip deformity is surgical correction. ${ }^{2}$ In the present case, this was carried out purely because of cosmetic reasons. Frenectomy was done to relieve tension in the midline papilla and also thought that it was aiding in folding of the tissue. Surgical procedure can be carried out either under local or general anaesthesia. Local infiltration was chosen as the method of administering anaesthesia in this case because along with providing adequate anaesthesia, it also helps in obtaining haemostasis for a clean surgical field. Different surgical techniques that have been described in the literature to remove redundant labial tissue are: W-plasty, excision by elliptical incision for patients without central constriction, and double ellipse incision with vertical Z-plasty in patients with short midline constriction and triangular incision. ${ }^{2}$ Simple transverse elliptical incision was utilised in our patient as he presented with double lip, without midline constriction. ${ }^{2}$ The choice of surgical approach usually depends on the condition of the lip tissue, preference and experience of the surgeon concerned. ${ }^{2}$ In the present case, surgery involved the excision of excess mucosa and submucosa without involving the underlying muscular layer. The patient was evaluated on follow-up and he was satisfied with the results.

Conflict of Interest: None 


\section{REFERENCES}

1. Martins WD, Westphalen FH, Sandrin R, Campagnoli E. Congenital maxillary double lip: review of the literature and report of a case. J Can Dent Assoc. 2004 Jul-Aug;70(7):466-8.

2. Bhattacharya H, Agarwal M, Gummaluri S, Agarwal A. Surgical correction of congenital double lip. Ann Maxillofac Surg. 2020 Jan 1;10(1):198-202.

3. Daniels JSM. Congenital double upper lip: A case report and review of the literature. Saudi Dent J. 2010 Jul;22(3):101-6

4. Ariyawardana A. Congenital double upper lip: Review of literature and report of a case. J Investig Clin Dent. 2011 Aug 1;2(3):212-5.

5. Palma MC, Taub DI. Recurrent double lip: Literature review and report of a case. Oral Surg Oral Med Oral Pathol Oral Radiol Endod. 2009;107(3):20-3.

6. Khatri A, Kalra N, Tyagi R, Poswal A, Panwar G, Garg K. Double Lip - An atypical facial anomaly: Two case reports. Int J Clin Pediatr Dent. 2018;11(5):451-5.

7. Eski M, Nisanci M, Aktas A, Sengezer M. Congenital double lip: Review of five cases. Br J Oral Maxillofac Surg. 2007 Jan;45(1):68-70. 